\title{
LA REFORMA ECONÓMICA EN CUba tras la APROBACión DE LA Nueva Constitución en 2019
}

\author{
The Economic Reform in Cuba after the approval of the new \\ Constitution in 2019
}

\section{JACQUELINE LAGUARDIA MARTÍNEZ}

The University of West Indies, Trinidad and Tobago

\begin{abstract}
RESUMEN
El artículo evalúa la evolución del proyecto cubano de cambio económico plasmado en los Lineamientos de la Política Económica y Social del Partido y la Revolución. Casi una década después de su aprobación, estamos en condiciones de identificar avances e insuficiencias y señalar obstáculos que este inacabado proceso previsiblemente habrá de enfrentar, de conjunto con sugerencias de acción para su avance. Tras hacer referencia a etapas precedentes de reformas económicas, se analiza la progresión de los Lineamientos hasta 2019, año trascendente para el país a raíz de la aprobación de una nueva Constitución. Para esta evaluación se tuvieron en cuenta indicadores macroeconómicos, la narrativa dominante en el discurso público de los decisores de política en Cuba así como opiniones de reconocidos estudiosos de la economía y la sociedad cubanas residentes dentro y fuera de la isla. Se incorporó el análisis del contexto internacional como factor de peso en la política económica cubana, con énfasis en la condición de Cuba como Pequeño Estado Insular en Desarrollo -circunstancia a menudo subestimada tanto por los funcionarios públicos como por los críticos del modelo cubano.
\end{abstract}

Palabras clave: reforma económica, Pequeños Estados Insulares en Desarrollo (PEID), Cuba, Lineamientos, Constitución.

\begin{abstract}
The article evaluates the evolution of the Cuban economic reform embodied in the Guidelines on the Economic and Social Policy of the Party and the Revolution. Almost a decade after its approval, we assess progress and shortcomings while pointing out obstacles for the process to advance, together with suggestions on courses of action to continue the reform. After referring to previous attempts of economic change, we analyze the advancement of the Guidelines until 2019, a key year for Cuba since a new Constitution was approved. For this assessment were examined macroeconomic indicators, policy makers' public discourse and academic papers published by renowned scholars of Cuban economy and society. The analysis of the international situation was considered with an emphasis on Cuba's condition as Small Island Developing State - a factor that has often been underestimated by policy makers as well as by critics of the Cuban model.
\end{abstract}

Keywords: economic reform, Small Island Developing States (SIDS), Cuba, Guidelines, Constitution. 


\section{INTRODUCCIÓN}

En julio de 2006 el general Raúl Castro asumió, de manera provisional, la Presidencia de los Consejos de Estado y de Ministros de la República de Cuba. En febrero de 2008, en Sesión de la Asamblea Nacional del Poder Popular (ANPP), los diputados cubanos lo eligieron como Presidente tras la renuncia pública de Fidel a ser nominado como candidato para el cargo por serios problemas de salud.

La llegada de Raúl Castro a la presidencia trajo consigo la promoción de una nueva ola de transformaciones con el propósito de recuperar la economía, que ya comenzaba a sentir los embates de la crisis financiera y económica global y había sido seriamente afectada por la ocurrencia de eventos climatológicos extremos como sequías y huracanes. Sin embargo, no era esta la primera vez que Cuba aprobaba un plan de reformas para reactivar su modelo económico, caracterizado por la presencia dominante del Estado y donde las relaciones mercantiles se subordinan a la planificación centralizada. Esfuerzos similares fueron impulsados años antes y también en situaciones de marcado estrés económico. De cada uno de estos intentos se heredó un balance mixto de logros y fracasos.

En común, estos experimentos compartían el objetivo de colocar a la economía cubana en una senda de crecimiento estable, disminuir la dependencia externa y crear resiliencia ante crisis coyunturales y amenazas permanentes. El propósito mayor era alcanzar un desarrollo socioeconómico donde se combinaran actividades diversas capaces de garantizar la satisfacción de niveles mínimos de la demanda doméstica. En estos modelos, la ciencia y la innovación estarían funcionalmente integradas al conjunto de los sectores de la economía, se generarían suficientes empleos de calidad y el conjunto de todos los territorios y comunidades serían beneficiados. Como consecuencia, el país habría modificado su patrón de inserción internacional heredero de lógicas coloniales que dieron al Caribe un papel subordinado en la economía globalizada que nace con la Modernidad y que hoy se traduce, para Cuba, en un déficit crónico de balanza de pagos, concentración de las exportaciones, acceso tortuoso a flujos financieros y de inversión, creciente endeudamiento, escasez en la oferta de bienes y servicios, entre otros problemas asociados a la geopolítica hemisférica y mundial donde la naturaleza de las relaciones con los Estados Unidos juega un peso significativo.

El objetivo de este artículo es analizar lo conseguido, hasta 2019, por la propuesta de reforma asociada al proyecto Lineamientos de la Política Económica y Social del Partido y la Revolución (a partir de ahora Lineamientos) (PCC 2011). Vale señalar que si bien este proyecto fue aprobado en 2011, ya desde 2008 se había comenzado la introducción de algunos cambios.

A partir de la revisión de las etapas precedentes de cambio económico en Cuba, se comparan las propuestas de los Lineamientos con indicadores macroeconó- 
micos disponibles hasta 2019 a la vez que se analiza el impacto de factores externos en la política económica, con énfasis en la condición de Cuba como Pequeño Estado Insular en Desarrollo (PEID). En el análisis se otorgó especial atención a la realización del referendo constitucional en febrero de 2019 y la entrada en vigor de la nueva Constitución de la República de Cuba en abril de ese mismo año.

Para la elaboración de este artículo nos basamos en el empleo de la revisión documental que incluyó bases de datos especializadas, documentos oficiales y pronunciamientos públicos de representantes del gobierno cubano. Como parte de la revisión de fuentes secundarias se examinó literatura científica contenida en libros y artículos académicos, textos de opinión y reportes periodísticos producidos en Cuba y el extranjero. La amplia revisión documental permitió contrastar el análisis de los contenidos emitidos por diferentes actores -con posicionamientos diversos ante el proceso de reforma y el modelo cubano- con indicadores económicos que reflejan la evolución de la reforma y sus impactos en la economía cubana hasta 2019. Se empleó información cuantitativa y cualitativa.

La investigación puede ser clasificada como descriptiva-explicativa al ubicar su propósito central en el establecimiento de los rasgos específicos que caracterizan la evolución de la reforma económica emprendida por Cuba. Tras este paso inicial, estamos en condiciones de contribuir a una comprensión más completa acerca de su progresión, impactos y desafíos en el contexto de una sociedad que se transforma aceleradamente y que, desde abril de 2019, opera bajo los marcos establecidos en una nueva Carta Magna. La investigación persigue motivar nuevas lecturas sobre la economía, política y sociedad cubanas, a la vez de aportar argumentos a la discusión sobre el rumbo de la reforma y las transformaciones pendientes en Cuba en pos del crecimiento económico y el desarrollo sostenible en un contexto de mayor inclusión y justicia social.

Vale resaltar que tanto la reforma económica como la Constitución de 2019 han generado extenso debate y abundante material analítico dentro y fuera de la isla. En el caso de la reforma, la mayoría de los estudios coinciden al identificar fallos y obstáculos, mientras difieren en las propuestas sobre cómo, cuándo, cuánto y hacia qué avanzar. En relación con la Constitución, las discusiones se han centrado en las continuidades y diferencias con la Carta Magna remplazada -que databa de 1976- y la correspondencia del texto adoptado con la realidad de una sociedad que ha experimentado transformaciones rotundas en los últimos treinta años.

\section{LAS CLAVES DE LOS LINEAMIENTOS ¿UN INTENTO DE REFORMA “DIFERENTE"?}

A partir del 2008 cambió el rumbo en la conducción de la economía y la política en Cuba. Entre las modificaciones introducidas que reorientaron el movimien- 
to pendular de la batalla ideológica -más conocida durante inicios de siglo como Batalla de Ideas- hacia la batalla económica, sobresalen la ampliación de la oferta en la red de comercio minorista, el acceso a servicios de telefonía celular y a instalaciones turísticas, la flexibilización en la formación de los salarios, la recontratación de jubilados, la práctica del pluriempleo y la entrega de tierras ociosas en usufructo (Pérez Villanueva 2008: 50).

En el propósito de impulsar estos cambios se convocó a un debate público para discutir un proyecto de modelo socioeconómico y maneras de alcanzarlo. Esta convocatoria tenía como antecedente inmediato el debate popular de la segunda mitad de 2007 lanzado para discutir críticamente los problemas de la realidad cotidiana. ${ }^{1}$ Tales convocatorias no constituyeron novedad en Cuba donde la aprobación de anteriores programas de reforma fue antecedida por la celebración de asambleas populares. En el caso que aquí analizamos, las reuniones se extendieron desde diciembre de 2010 hasta febrero de 2011, días antes de celebrarse el VI Congreso del Partido Comunista de Cuba (PCC). ${ }^{2}$

Durante el Congreso, los delegados aprobaron el proyecto de los Lineamientos cuyo fin expreso es "actualizar" el modelo económico y social. La discusión hizo referencia a la voluntad de "actualizar", locución verbal que se antoja menos agresiva si se compara con "reformar" y que remite al espíritu de continuidad que el gobierno enfatizara desde el retiro de Fidel Castro de la vida política activa, a la vez que se distancia del tipo de reformas emprendidas por los países socialistas de Europa del Este y que derivaron en un retorno al capitalismo. De acuerdo al Jefe de la Comisión Permanente para la Implementación y Desarrollo de los Lineamientos, Marino Murillo: "La actualización del modelo económico cubano, a partir de los Lineamientos aprobados, lo que presupone es modernizar la gestión, hacer la propiedad eficiente y desarrollar las fuerzas productivas." (Rosabal 2013). En otras palabras, de lo que se trata es de perfeccionar el Socialismo, no de abandonarlo.

Desde el triunfo de la Revolución, han sido varios los intentos de transformaciones en pos de impulsar determinadas visiones de desarrollo, siempre en dependencia de situaciones políticas y económicas concretas dentro y fuera del país. Las etapas que distinguen las estrategias de desarrollo previas, edificadas desde principios e instrumentos de política económica específicos, son: (i) período 1959-1960: propiedad estatal como base para el proceso de

\footnotetext{
“Como respuesta a esa convocatoria, se efectuaron en todo el país 215.687 reuniones organizadas por el PCC y la UJC, así como por las organizaciones sociales y de masas, juveniles y estudiantiles antes mencionadas. Según los datos difundidos, en estas participaron cerca de 5 millones de personas" (Suárez Salazar 2017: 34).

2 “(...) entre el $1^{\circ}$ de diciembre de 2010 y el 28 de febrero de 2011, se habían realizado en todo el país más de 163.000 reuniones convocadas por las diferentes organizaciones de raigambre popular que actúan en la sociedad política y en la sociedad civil cubana" (Suárez Salazar 2017: 35).
} 
desarrollo; (ii) período 1961-1963: industrialización por sustitución de importaciones; (iii) período 1964-1975: industrialización a partir del pivote agropecuario; (iv) período 1976-1989: industrialización en el marco de la División Internacional Socialista del Trabajo y; (v) período 1990-2008: resistencia durante la crisis del Período Especial y reinserción en la economía internacional. Estos períodos cuentan, a su vez, con sub etapas (Pérez Villanueva 2008: 32; Rodríguez 2019c: 52).

Los antecedentes directos de la presente etapa se corresponden con las transformaciones que se sucedieron a raíz de la desaparición de la URSS y el campo socialista, eventos estos que interrumpieron el programa de cambios denominado Proceso de Rectificación de Errores y Tendencias Negativas de mediados de los 80 's. El espíritu de los Lineamientos recupera buena parte de las innovaciones que se introdujeron durante los 90's , algunas de las cuales fueron descontinuadas, parcialmente abandonadas o desechadas del todo una vez que el escenario económico y geopolítico regional cambió a inicios de siglo.

De acuerdo a Alonso Tejada (2009), las sub etapas de la reforma en los 90's son: (i) período 1989-1993: shock de desconexión caracterizado por la apertura al capital extranjero, impulso al turismo y la industria médica como sectores estratégicos; (ii) período 1993-1995: reformas estructurales y contención de la caída caracterizado por la libre circulación del dólar, la recuperación del trabajo por cuenta propia, la desestatización de la producción agraria y la eliminación de gratuidades; y (iii) período después de 1995: reanimación económica caracterizada por nueva legislación tributaria, restructuración del sistema bancario y medidas para el perfeccionamiento de la empresa estatal socialista (Alonso Tejada 2009: 318-319).

Según Serbin (2019), la fase iniciada en 2008 da continuidad a las etapas de transformación de los 90's, así como a nuevos cambios de principios de siglo. Entre estos últimos, sobresale el mayor dinamismo en las tasas de crecimiento e inversiones significativas en salud y educación de conjunto con la descapitalización de la agroindustria azucarera y el quiebre de la disciplina monetaria (Serbin 2019: 4). Téngase en cuenta que, a inicios del siglo XXI, la economía cubana ya se había recuperado de los momentos más álgidos del Período Especial y la ola rosa de gobiernos latinoamericanos progresistas abiertamente cordiales hacia la Revolución Cubana -Hugo Chávez en Venezuela, Lula en Brasil, los Kirchner en Argentina, Evo Morales en Bolivia, Rafael Correa en Ecuador y Leonel Fernández en República Dominicana- permitió al país reordenar sus prioridades de política y dirigir la atención a la recuperación e impulso a programas sociales como respuesta al deterioro en la prestación de servicios públicos y el incremento de desigualdades sociales acumuladas desde finales del siglo anterior. 
Tabla 1. Comparación de los fundamentos guías de los Lineamientos con intentos previos de reforma económica en Cuba (mediados de los 60's - 2011)

\begin{tabular}{l} 
Lo similar \\
\hline $\begin{array}{l}\text { No se trata de reformar, sino de rectificar, reno- } \\
\text { var, actualizar. }\end{array}$ \\
La continuidad del Estado Socialista, del pa- \\
pel central del PCC y del modelo de economía \\
central planificada no es cuestionada. \\
La experiencia de Cuba es única y no admite \\
comparaciones con experiencias foráneas. \\
Los contenidos de la reforma fueron debati- \\
dos en amplios procesos de debate popular. \\
La reforma fue aprobada y es conducida, mo- \\
nitoreada, evaluada, impulsada y controlada \\
por el PCC.
\end{tabular}

El Estado mantiene su papel regulador en la política de precios.

La empresa estatal socialista es el actor central de la actividad productiva.

Se mantienen mecanismos centralizados para la distribución y la comercialización de bienes y servicios esenciales.

Se reconoce la contribución de la Inversión Extranjera Directa (IED) al crecimiento económico.

Se ratifica el concepto de igualdad de derechos y de oportunidades para todos los ciudadanos.

Se reconoce el carácter universal de la política social que garantiza el acceso a servicios de educación, salud, cultura y deporte, seguridad y asistencia sociales.

No se permitirá la concentración de la propiedad en las formas de gestión no estatales.

\section{Lo novedoso}

El modelo de gestión reconoce, de conjunto con la empresa estatal socialista, las modalidades de inversión extranjera, las cooperativas -en otros sectores además del agro-, los agricultores pequeños, los usufructuarios, los arrendatarios y los trabajadores por cuenta propia como actores económicos.

Se apuesta por mantener el programa acordado en los Lineamientos a pesar del reconocimiento explícito por el PCC del progreso insuficiente en su VII Congreso de 2016. En 2017 se aprueban dos nuevos documentos para la continuación y perfeccionamiento de la reforma.

Se reconoce en las formas económicas no estatales un actor de carácter permanente en la economía.

Se abre la posibilidad para una Ley de Quiebra Empresarial.

Se reconoce a la IED como modalidad a promover para la recuperación y relanzamiento de la economía.

Se promueve la creación de Zonas Especiales de Desarrollo.

Se especifica que igualdad no significa igualitarismo.

Se indica la eliminación ordenada y gradual de la libreta de abastecimiento. En vez de subsidiar productos, se propone extender subsidios a las personas y grupos más vulnerables.

Se reconoce la compraventa de viviendas y otras formas de transmisión de la propiedad entre personas naturales.

Las propuestas de los Lineamientos buscan superar un escenario marcado por el sobredimensionamiento del sector público, la baja productividad, la descapitalización de la industria, la insuficiente producción agrícola y la presión demográfica (Serbin 2019: 5). De acuerdo con los Lineamientos, los cambios a introducir han de enfrentar los problemas siguientes en el corto y más largo plazos: 
Soluciones a corto plazo, encaminadas a eliminar el déficit de la balanza de pagos, que potencien la generación de ingresos externos y la sustitución de importaciones $y$, a su vez, den respuesta a los problemas de mayor impacto inmediato en la eficiencia económica, la motivación por el trabajo y la distribución del ingreso, y creen las necesarias condiciones infraestructurales y productivas que permitan el tránsito a una etapa superior del desarrollo.

Soluciones del desarrollo sostenible, a más largo plazo, que conduzcan a una autosuficiencia alimentaria y energética altas, un uso eficiente del potencial humano, una elevada competitividad en las producciones tradicionales, así como el desarrollo de nuevas producciones de bienes y servicios de alto valor agregado. (PCC 2011: 10).

El proceso de los Lineamentos ha ido acompañado de transformaciones en la institucionalidad política, similar a lo ocurrido en etapas anteriores, recuérdese la Reforma Constitucional de 1992, por ejemplo. Tales ajustes resultan necesarios en aras de dotar a la reforma de un marco político-institucional coherente con los cambios previstos y donde se reconozcan a actores económicos diversos. En febrero de 2019, tras un proceso de consulta ciudadana de alrededor de tres meses, fue aprobada por referéndum popular una nueva Constitución, que entró en vigor en abril de ese mismo año.

\section{LA CONSTITUCIÓN DE 2019}

Ya desde la aprobación de los Lineamientos quedó claro que el Estado cubano requería de modificaciones sustanciales en el ordenamiento político y jurídico. Justamente, una de las evidencias más interesantes que cuestionan el empeño de las autoridades cubanas de hablar de "actualización" -en vez de reconocer que se está ante un proceso más profundo de transformaciones- lo constituye la convocatoria a redactar y adoptar un texto constitucional nuevo. La Constitución de 1976, que incorporó varias enmiendas en 1978, 1992 y 2002 encaminadas a hacer compatibles los cambios y nuevas circunstancias que se iban acumulando en la sociedad cubana, no resistiría el cúmulo de adecuaciones necesarias para evitar que los Lineamientos aprobados por el PCC y documento rector de la política económica entraran en franca contradicción con la ley primera de la República.

Tal realidad fue reconocida Homero Acosta, secretario del Consejo de Estado y miembro de la Comisión de Reforma Constitucional. En julio de 2018 en el marco del Primer Período Ordinario de Sesiones de la IX Legislatura de la ANPP, Acosta reconocía que se estaba ante la discusión de una nueva Constitución y no de la reforma parcial de la Constitución de 1976 (Tirado 2018).

Si bien considero que la necesidad de dotar de coherencia a la reforma socioeconómica con el entorno político y normativo no fue el único motivo para la entrada en vigor de la nueva Carta Magna, sí creo que su elaboración, discusión y promulgación resultaron favorecidas por la voluntad de adecuar el ordena- 
miento jurídico del país a la sociedad descrita en los Lineamientos. Desde esta perspectiva, la aprobación de la Constitución se considera una acción más dentro del marco de ese proceso de reformas que incluye y antecede a la implementación de los Lineamientos, y que se caracteriza por el paulatino aumento del sector privado, los espacios ganados para el debate público y la participación activa de actores diversos en las dinámicas sociales en Cuba. Eso sí, se trata de una acción de suma relevancia que introduce elementos y modificaciones novedosas.

Entre las diferencias más significativas de la Constitución de 2019 con su predecesora, destacamos las siguientes:

Tabla 2. Principales modificaciones incorporadas en la Constitución de la República de Cuba aprobada en 2019.

\begin{tabular}{l} 
Modificaciones \\
\hline Límite de mandato presidencial a dos períodos consecutivos de cinco años \\
Edad mínima para aspirar a la presidencia establecida en 35 años y edad máxi- \\
ma de 60 años en la primera postulación \\
Restauración de la figura del Primer Ministro \\
Creación de las figuras de los gobernadores y vicegobernadores provinciales, y \\
de los intendentes municipales \\
Expansión y fortalecimiento de la autonomía de los territorios y los gobiernos
\end{tabular}
locales (provincias y municipios)

Artículo(s)

Reconocimiento explícito del carácter laico del Estado

126

$140-144$

Disposiciones transitorias

$167-169$

Reconocimiento a los yacimientos minerales y las playas como parte de la propiedad socialista de todo el pueblo

Reconocimiento de la propiedad privada por parte de personas naturales o jurídicas, cubanas o extranjeras

Reconocimiento de la propiedad de instituciones y otras formas asociativas

Reconocimiento de la inversión extranjera como elemento para el desarrollo económico, a la que se asegura promoción y garantías

Reconocimiento del derecho a la doble ciudadanía

Reconocimiento del carácter imprescriptible, indivisible, universal e interdependiente de los derechos humanos

Ampliación de los derechos fundamentales como acceso al agua, al medio ambiente sano y equilibrado, a la alimentación, a una vivienda adecuada, a la educación hasta los estudios de posgrados, a servicios de salud de calidad, entre otros

Expansión de las garantías de los derechos sexuales y reproductivos de las mujeres, y protección contra la violencia de género

Reconocimiento del derecho de cada persona de establecer una familia cualquiera que sea su forma de organización

$46-80$

Establecimiento de garantías constitucionales como el debido proceso, el habeas corpus, la presunción de inocencia en los procesos penales, la tutela judicial efectiva, el acceso a un proceso sin dilaciones indebidas, recibir reparación por los daños materiales y morales e indemnización por los perjuicios, entre otras 
Durante los debates públicos, la ciudadanía expresó inconformidad con varios de los artículos incluidos en el Proyecto Constitucional y propuso ajustes y adiciones. Como resultado fueron añadidos dos Secciones y cinco Artículos. Fueron modificados ocho párrafos del preámbulo y 134 Artículos -alrededor del $60 \%$ del total. Tres Artículos se eliminaron y solo 87 permanecieron sin alteraciones. En total, la comisión redactora introdujo 760 cambios (Figueredo Reinaldo et al. 2018).

No todo lo propuesto por la ciudadanía fue incorporado por la comisión, lo que demuestra el uso de criterios discrecionales en la revisión y redacción del texto final. Por ejemplo, se recogieron 16,176 propuestas para modificar el Artículo que establecía que la elección del Presidente de la República era potestad de la ANPP. La mayoría de estas propuestas abogó por establecer la elección directa al cargo de la Presidencia de la República (Figueredo Reinaldo et al. 2018). En el texto aprobado se mantuvo inalterada la formulación inicial (Artículo 126). El sistema electoral cubano permite a los ciudadanos con derecho al voto la elección directa de los representes a nivel de barrio, municipio y provincia, pero no a la máxima representación del gobierno. También se mantuvieron inalterables la reafirmación de la ideología socialista del Estado (Artículo 1), la irrevocabilidad del sistema socialista (Artículo 4) y el carácter del Partido Comunista de Cuba como "fuerza política dirigente superior de la sociedad y del Estado" (Artículo 5).

La nueva Constitución contiene vacíos importantes. En relación estrecha con la ejecución de los Lineamientos, destaca la falta de precisión en la división entre propiedad personal y privada. Otros vacíos se refieren a la ausencia de límites formales a la actuación del PCC y el no reconocimiento de un mecanismo de control constitucional de tipo jurisdiccional. Si bien se reconoce la libertad de prensa, pensamiento, conciencia y expresión, no se incluyen garantías específicas para su ejercicio ni se reconoce el derecho al acceso y uso de tecnologías de la información y la comunicación (García Castro y Peña Barrio 2019). Se espera que buena parte de las ausencias identificadas sean enmendadas una vez que se debatan y adopten las leyes complementarias a la nueva Carta Magna. En diciembre de 2019, la ANPP aprobó su cronograma legislativo conformado por 39 leyes y 31 decretos leyes a aprobar hasta 2022 (ANPP 2019).

El mayor mérito de la Constitución ha sido codificar como ley buena parte de las transformaciones experimentadas por la sociedad cubana como consecuencia de las reformas iniciadas hace más de una década y que no eran legales de acuerdo a lo establecido en la Carta Magna de 1976. La nueva Constitución dota de amparo legal a los cambios aprobados dentro de los Lineamientos, amplía el espectro de derechos explícitamente reconocidos a la ciudadanía y tiene el potencial de redundar en una mejor definición de las atribuciones y facultades de las instituciones y autoridades del Estado a partir de la coexistencia del Presidente, el Primer Ministro, el Presidente del Consejo de Estado y el Primer Secretario del PCC. 
De acuerdo a lo estipulado en la Carta Magna, durante la IV Sesión Extraordinaria de la ANPP celebrada en octubre de 2019, resultó electo como Presidente de la República de Cuba el diputado Miguel Mario Díaz-Canel Bermúdez quien desde abril de 2018 se desempeñaba como Presidente del Consejo de Estado y del Consejo de Ministros. En diciembre de 2019, fue aprobada por la ANPP la designación de Manuel Marrero Cruz para el cargo de Primer Ministro. Marrero Cruz estaba, hasta entonces, al frente de la cartera de Turismo. En enero de 2020 fueron electos los gobernadores y vicegobernadores en las provincias y, a propuesta de las Asambleas Municipales del Poder Popular, fueron designados los 168 intendentes al frente de los Consejos de la Administración Municipal.

\section{LA POLÍTICA Y GESTIÓN ECONÓMICAS: BALANCE HASTA 2019}

Si bien 2019 fue un año de avances importantes en el marco normativo que ha de apoyar la reforma económica, no puede concluirse lo mismo sobre el estado de la economía cubana. El desempeño económico no ha cumplido con las expectativas y el crecimiento del PIB en los últimos años se ha mantenido, como tendencia, por debajo del 3\% anual.

Gráfico 1. Tasa de crecimiento del PIB a precios constantes. Años 2013 - 2019 (\%).

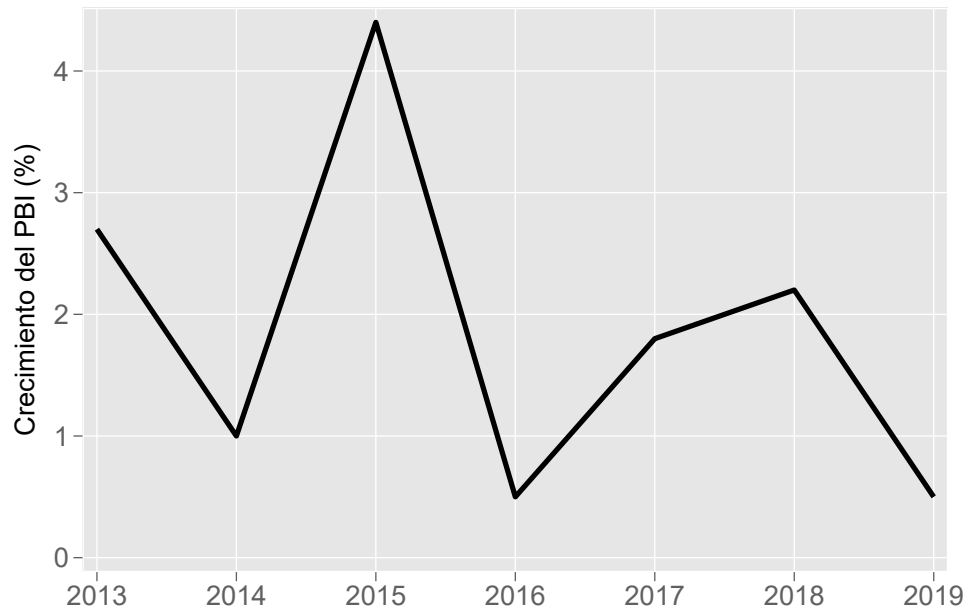

Fuentes: ONEI 2019, CEPAL 2019.

A pesar del débil crecimiento, Cuba ha sido capaz de diversificar sus relaciones económicas si bien persiste una marcada concentración de su comercio con un 
reducido grupo de países. Dentro de ellos resalta Venezuela, el mayor proveedor de combustibles a la isla a pesar de que la participación venezolana en el comercio bilateral de bienes ha disminuido en años recientes -reducción asociada a la crisis económica que atraviesa la nación sudamericana.

Como promedio, entre 2013 y 2018, Venezuela acaparó el 27\% del total del intercambio comercial de mercancías con Cuba. Le siguen China y España, con promedios de alrededor de $14 \%$ y $10 \%$ respectivamente $\mathrm{y}$, entre los tres, absorben la mitad del total. El conjunto de los diez principales socios en el comercio de bienes con la isla representa alrededor del 70\%.

Gráfico 2. Intercambio de bienes con los diez principales socios comerciales. Años 2013 - 2018 (\% del total).

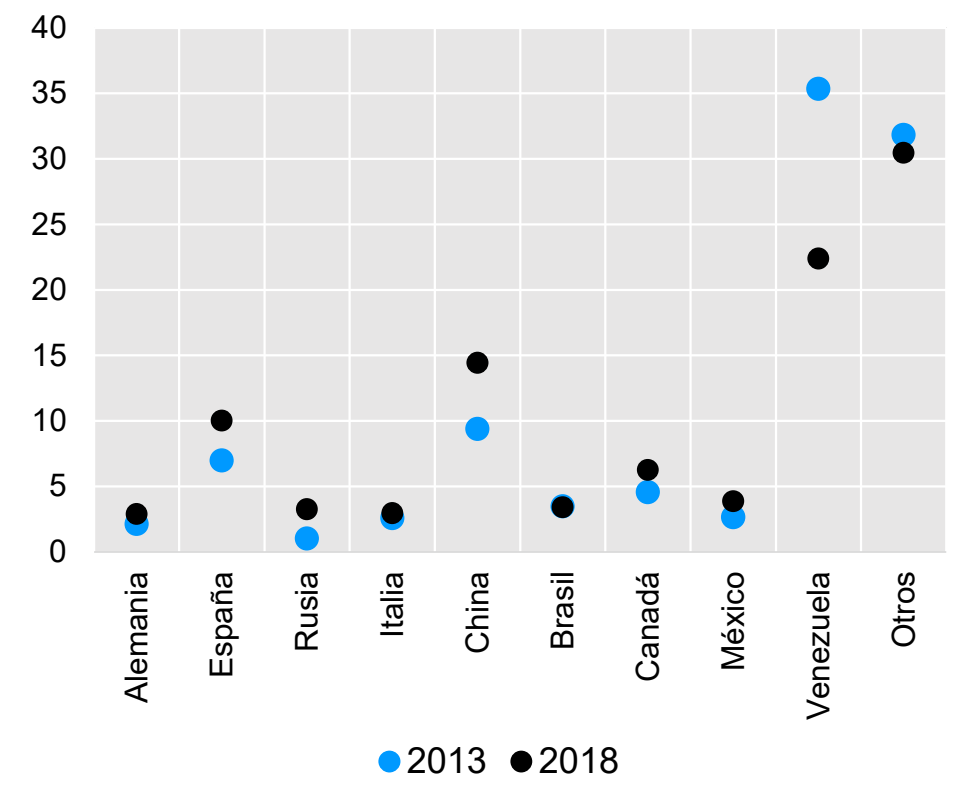

Fuente: ONEI 2019.

La concentración también se manifiesta al examinar los principales rubros de bienes exportables de Cuba. Entre 2013 y 2018, cuatro categorías concentraron, como promedio, el 67\% de las exportaciones. Esta proporción, lejos de disminuir, aumentó en los últimos años. En 2013, este agregado de cuatro categorías representaba $46 \%$ del total de los bienes exportados -menos de la mitad- mientras que, en 2018, su participación ascendía al 83\% (ONEI 2019). 
Gráfico 3. Principales rubros de exportaciones de bienes según la CUCI. ${ }^{3}$ Años $2013-2018$ (\%).

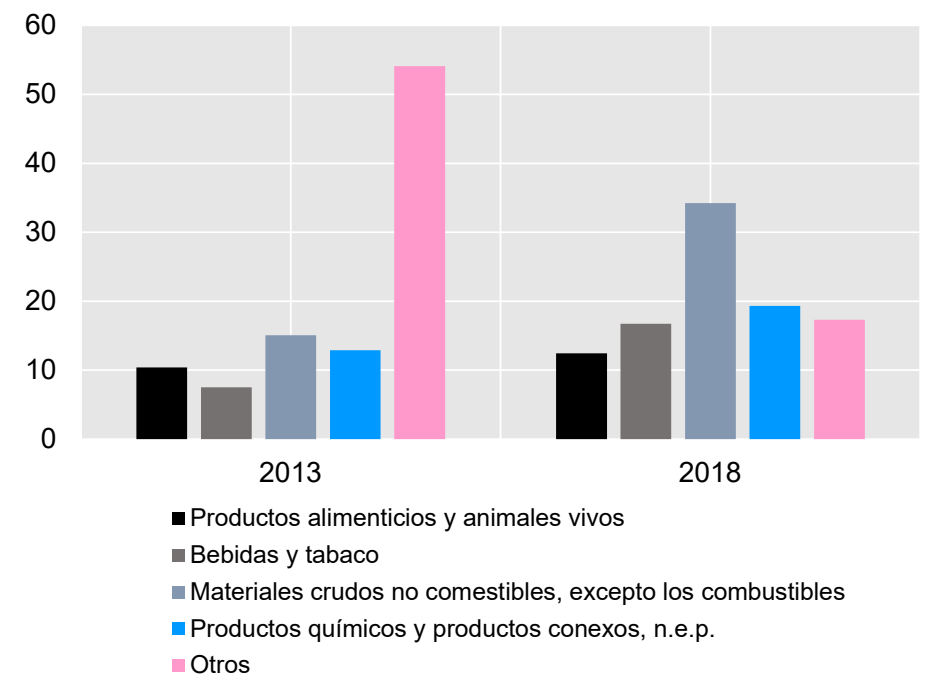

Fuente: ONEI 2019

Como parte de la estrategia de diversificación de su cartera de exportaciones, vale destacar que la isla logró incrementar su participación como proveedor de servicios. Además de la actividad turística, pilar económico central para Cuba -similar a la mayoría de los PEID caribeños-, el país se ha especializado en la prestación de servicios profesionales entre los que sobresalen los servicios de enseñanza que representaron 250,085.2 miles de pesos en 2018, mientras los servicios de salud produjeron exportaciones por un valor de 6,398,538.8 miles de pesos ese mismo año. En los últimos años, Cuba exhibe un superávit en el comercio de servicios, que en 2018 ascendió a 10,247,581.3 miles de pesos (ONEI 2019).

El incremento de las exportaciones de servicios ha permitido mejorar los saldos de la cuenta corriente de balanza de pagos y, gracias a ello, Cuba mantiene un saldo positivo en el intercambio comercial total. Sin embargo, entre 2013 y 2018, la isla registró una reducción de $22 \%$ de sus exportaciones acompañada de una contracción de 19.4\% en importaciones (Rodríguez 2019b: 95).

Las exportaciones de servicios, por otra parte, no han sido capaces de generar el efecto multiplicador que antes tuvieron las exportaciones industriales y de azúcar, a pesar de su importante expansión en la última década (Romero 2017: 
52). Persiste la débil articulación entre el sector exportador y las capacidades internas y no se registran avances de peso en el proceso de sustitución de importaciones.

Tabla 3. Importaciones de bienes agrupadas en grandes categorías económicas, según la CUCI. Años 2013 - 2018 (millones de pesos).

\begin{tabular}{ccccccc}
\hline Categoría & 2013 & 2014 & 2015 & 2016 & 2017 & 2018 \\
\hline Bienes de consumo & 1882 & 1963 & 2167 & 2085 & 2134 & 2311 \\
Bienes intermedios & 11313 & 9890 & 7842 & 6470 & 6491 & 7587 \\
Bienes de capital & 1512 & 1184 & 1693 & 1715 & 1547 & 1586 \\
Total & 14707 & 13037 & 11702 & 10270 & 10172 & 11484 \\
\hline
\end{tabular}

Fuente: ONEI 2019

La creación de la Zona Especial de Desarrollo de Mariel y la promulgación de una nueva Ley de Inversión Extranjera en 2014 no ha logrado recuperar la tasa de inversión con relación al PIB, la que promedia alrededor del 10\% en los últimos años. Los cálculos indican que se necesita de una tasa superior al $20 \%$ como mínimo para mantener un ritmo de crecimiento del PIB anual de, al menos, 5\% (Rodríguez 2016; Rodríguez 2019a).

Un componente importante de la reforma lo constituye la reestructuración del sector estatal. No solo del Estado como actor económico clave que opera a través de la empresa estatal socialista y en asociación con el capital extranjero, sino también como agente central en el diseño, ejecución y evaluación del plan económico y los programas de desarrollo. Una de las primeras medidas adoptadas, iniciada incluso antes de la aprobación de los Lineamientos, fue la fusión y reconversión de entidades estatales con el propósito de racionalizar plazas, agilizar trámites y facilitar la implementación de políticas. El nuevo escenario apunta a que los organismos de la Administración Central han de aprender a operar con presupuestos más reducidos.

Como parte de la reestructuración se orientó a los ministerios prescindir de sus funciones empresariales, las que quedarían a cargo de entidades subordinadas como los Grupos Empresariales. Ejemplos de estos ajustes son la transformación del Ministerio de la Industria Básica en Ministerio de Energía y Minas, la creación de un Ministerio de Industrias y la sustitución del Ministerio del Azúcar por el Grupo Empresarial AZCUBA.

El conjunto de las medidas adoptadas, dirigidas a un manejo más racional de los recursos del Estado entre otras acciones que han limitado el gasto estatal, han permitido la reducción del déficit fiscal que se mantiene elevado, pero en niveles manejables. 
Gráfico 4. Déficit fiscal como proporción del PIB. Años 2017 - 2019 (\%)

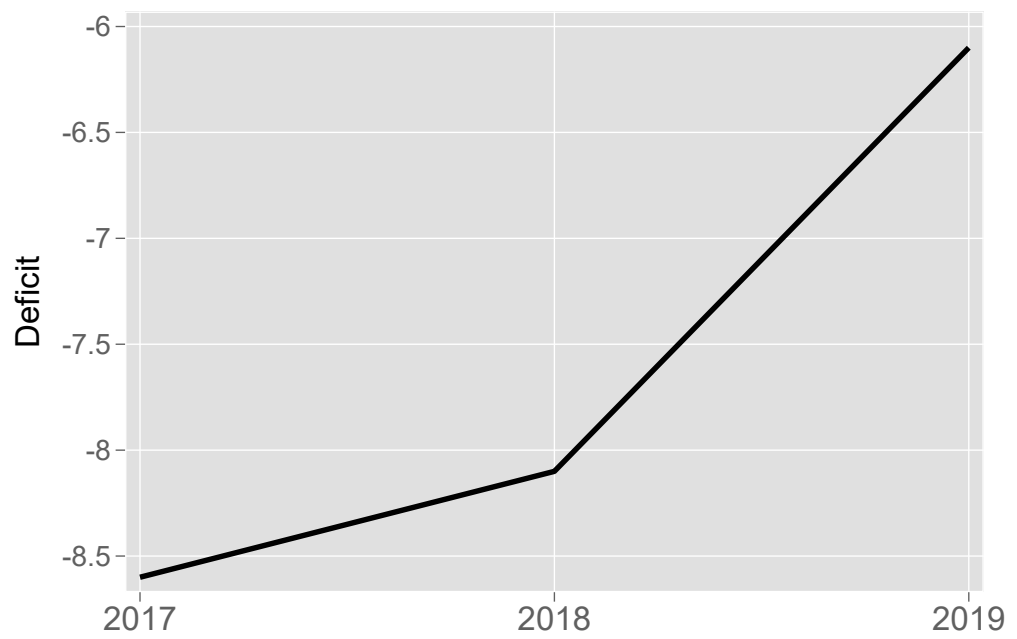

Fuente: Rodríguez 2019b.

Como consecuencia del reordenamiento del sector estatal aumentó el desempleo. No obstante, en 2019, el sector contaba aún con más de tres millones de empleados (Figueredo Reinaldo et al. 2019). Una salida importante para amortiguar el incremento del número de trabajadores excedentes fue la creación de empleos en el sector no estatal. Entre 2010 y 2017, el empleo privado aumentó de manera sostenida, en contraste con lo ocurrido en el sector público que perdió casi 153,000 puestos de trabajo mientras que el sector cooperativo no generó empleo neto (Monreal González 2017b). ${ }^{4}$

Vale destacar que, en Cuba, los incentivos al trabajo provienen fundamentalmente del sector no estatal y los jóvenes prefieren emplearse en el sector privado, donde estos representan el $24 \%$ de la fuerza laboral (Cubadebate 2015). Sin embargo, los recientes incrementos salariales en beneficio de los trabajadores del sector presupuestado podrían haber frenado parcialmente esta tendencia. En 2019 acudieron a la Direcciones de Trabajo 48,693 personas en busca de empleo, de los cuales el 49\% fueron jóvenes. Alrededor de 32,500 cubanos se sumaron al empleo en 2019 y, según valoraciones oficiales, esta es la primera vez desde 2016 que disminuye el número personas que ni estudian ni trabajan en el país (Figueredo Reinaldo et al. 2019).

La fuerza de trabajo de Cuba está constituida por unos 4,500,000 trabajadores. Casi el 30\% de ellos no está empleados en el sector público a diferencia de 1989 cuando casi el 90\% sí lo estaba (Torres Pérez 2017: 58). Ese $30 \%$ de la fuerza laboral está integrada por cuentapropistas, cooperativistas y empleados de empresas extranjeras o empresas mixtas (Torres Pérez 2017; Triana Cordoví 2017). Entre ellos, los cuentapropistas representaban, en 2017, el 42\% (Galtés Galeano 2017: 70). 
Aunque el tema central de los Lineamientos sea la reforma económica, el aspecto social no puede ser relegado en su implementación o evaluación. Existen en los Lineamientos propuestas de acciones en el ámbito de la política social, elemento crucial que influye en el crecimiento económico. Desde Cuba, se concibe la política social no solo como instrumento para mejorar de la calidad de vida a través de sus funciones preventivas, redistributivas y compensatorias, sino también como factor en la transformación de la estructura social y económica (Álvarez 1998).

Sin agotar aquí el análisis de este tema tan complejo, vale llamar la atención sobre el persistente aumento de la brecha de ingresos, a la que se suma las desigualdades de género y territoriales, prácticas discriminatorias por motivo del color de la piel y lugar de procedencia, y el deterioro en los niveles de satisfacción de las necesidades esenciales asociadas a alimentación, transporte, vivienda y calidad de los servicios básicos.

La mejora en las condiciones de vida de la mayoría de los cubanos a partir de 1959, alcanzada gracias a un conjunto de políticas sociales que promovieron la igualdad y la equidad desde la redistribución del ingreso, la seguridad nutricional, la creación de espacios de igualdad y la movilidad social ascendente, fue reflejada en una sostenida caída del Coeficiente GINI durante las primeras tres décadas que siguieron al triunfo de la Revolución (Valdés Paz 2014: 9). A mediados de los 80's, se estimaba el Coeficiente GINI en 0.24 (Espina Prieto 2008).

En contraste, estimaciones indican que, desde finales de los 90's hasta inicios del presente siglo, el Coeficiente GINI se ha deteriorado de 0.38 a 0.407 (Barbería 2008; Monreal 2017a). En 2000, el 20\% de los cubanos reportaba necesidades básicas insatisfechas (Espina Prieto 2008). Cálculos indican que el Coeficiente GINI en 2019 rondaba 0.45 y la pobreza por ingresos afectaba al 16\% de la población (Rodríguez 2019c).

Más allá de los avances mencionados en el comercio exterior y la reorganización del aparato estatal, a lo que se suma la renegociación de la deuda contraída con Rusia, México y el Club de París entre otros acreedores -lo que facilitó el acceso a préstamos y flujos financieros internacionales- subsisten en Cuba serios problemas que lastran el crecimiento y desarrollo económicos. Se mantiene el déficit en la balanza comercial de bienes, la oferta exigua en todos los mercados -incluido el mercado negro-, la insuficiente IED y el estancamiento productivo que presiona a favor de más importaciones y limita la expansión de las exportaciones de bienes (Rodríguez 2016; Triana Cordoví 2017; Mesa-Lago 2019).

A tales problemas se suman las restricciones crecientes a la expansión del sector no estatal de la economía expresadas en los escasos permisos otorgados para la creación de cooperativas no agropecuarias -suspendidos desde 2019-, 5 la lista

“La autorización en Cuba de las primeras cooperativas no agropecuarias tuvo lugar a inicios de 2013. Ese año se constituyeron 198 y después hubo un ligero ascenso, aunque de manera gradual se aprobaron cua- 
que restringe el tipo de actividades a realizar por ese sector, exigencias fiscales excesivas, la falta de una red de mercados mayoristas para su abastecimiento, el no reconocimiento de la figura jurídica de la pequeña y mediana empresa en el sector no estatal, entre muchas otras limitaciones.

Tales coerciones contradicen el reconocimiento que, en los Lineamentos y la Constitución, se le otorga al sector no estatal como elemento dinámico de la economía y, en particular, al sector privado. Recordemos que en su Artículo 22, al Constitución enumera las formas de propiedad reconocidas en Cuba, entre las que incluye a la propiedad privada como aquella "que se ejerce sobre determinados medios de producción por personas naturales" (Constitución de la República de Cuba 2019: 3).

Al aumento de las limitaciones al funcionamiento del sector no estatal se suma el nudo gordiano de la reforma: la unificación monetaria y cambiaria, tantas veces a las puertas y otras tantas pospuesta. Las distorsiones del régimen monetario se expresan en la coexistencia de varias tasas de cambio y de dos monedas de denominación nacional de curso legal -el CUP y el CUC-, a lo que se suma desde 2019 la posibilidad de emplear divisas libremente convertibles como medio de pago en establecimientos de la red de comercio minorista. ${ }^{6}$

La coexistencia de múltiples monedas, tasas de cambio y mercados oscurece los procesos de análisis y toma de decisiones a la vez que adultera la contabilidad y el sistema de cuentas nacionales, entre otros perniciosos efectos derivados de una tasa de cambio artificialmente sobrevaluada como son la dificultad para exportar y sustituir importaciones.

Los problemas antes identificados se agravan debido a obstáculos que, por el momento, no parece que desaparecerán en el corto, mediano y más largo plazo. De carácter más permanente mencionamos la reducida extensión territorial, la insularidad, la alta exposición a eventos meteorológicos extremos y la acentuada vulnerabilidad al cambio climático, es decir, la condición de Cuba como Pequeño Estado Insular en Desarrollo (PEID).

Los PEID constituyen un grupo de más de medio centenar de países y territorios que enfrentan retos particulares al desarrollo generalmente asociados a su relativamente reducida extensión territorial, condición insular y niveles preexistentes de desarrollo económico. Con una extensión superficial de casi 110 mil km² para todo el archipiélago cubano (ONEI 2019) y una población de

tro grupos, inicialmente, y el quinto grupo se quedó esperando. En la actualidad funcionan más de 400 cooperativas no agropecuarias, que agrupan a más de 17.000 socios. Están presentes en 10 sectores de la economía, con ingresos superiores a 6.000 millones de pesos. En 2019 entraron en vigor nuevas normas y se supo que no se crearían más cooperativas." (Pérez Villanueva 2020a).

6 La creación, en octubre de 2019, de tiendas minoristas para la venta en moneda libremente convertible, complica la unificación monetaria ante esta movida hacia la dolarización en la economía formal. Si bien no se utilizan divisas en efectivo para comprar -en estos establecimientos solo se permite el uso de tarjeta magnética - la divisa hubo de ser depositada previamente en una sucursal bancaria cubana, lo que indica una dolarización parcial. 
poco más de 11 millones de habitantes asentada en su mayoría en localidades urbanas (ONEI 2019), la mayor de las Antillas no clasifica dentro de los territorios más pequeños -ni por extensión ni por número de habitantes- dentro del grupo de PEID. Sin embargo, su marcada vulnerabilidad ante shocks exógenos asociada a su ubicación geográfica, condición insular, disponibilidad de fuentes de agua potable, tierras aptas para la agricultura, dotación de recursos naturales y de biodiversidad, estructura económica, patrones de inserción internacional y niveles medios de desarrollo socioeconómico justifica su inclusión en el grupo de PEID caribeños y ratifican que el país enfrenta un conjunto de dificultades específicas al desarrollo que, en buena medida, deben asumirse como valores constantes en la ecuación de la reforma económica. Cuba, al igual que el resto de los PEID, representa una contribución marginal en la emisión de gases de efecto invernadero. Sin embargo, son los territorios que sufren más, y de manera desproporcionada, de los impactos negativos del cambio climático.

Otro elemento de naturaleza cuasi permanente -pues no parece que habría de modificarse de manera sustancial en los próximos años- y que obstaculiza la reforma y el avance económico de la isla es el bloqueo/embargo estadounidense vigente desde inicios de los 60's y entronizado por la Administración Trump. ${ }^{7}$ El actual gobierno estadounidense ha apostado por retrotraer la relación bilateral a la confrontación hostil. Si bien se mantienen los lazos diplomáticos reestablecidos durante el gobierno del Presidente Obama, se han reducido al mínimo el contacto entre gobiernos y cancillerías, y se han restringido las opciones para que los estadounidenses visiten la isla. En 2018, 637,907 estadounidenses visitaron Cuba mientras que, en 2019, solamente lo hicieron 498,067 estadounidenses, tendencia que contrasta con lo ocurrido entre 2015 y 2017 cuando el arribo de visitantes desde Estados Unidos -incluyendo cubanoamericanos- creció a una tasa promedio anual de 44 \% (Vidal Alejandro 2019).

El intento de aumentar la presión económica sobre Cuba por parte de la Administración Trump ha desembocado en otras medidas tales como la activación del Título III de la Ley Helms-Burton por vez primera desde su promulgación en 1996, la prohibición de viajes a Cuba de cruceros, yates, aeronaves privadas y corporativas, la prohibición a aerolíneas comerciales estadounidenses de viajar a Cuba, la suspensión de vuelos comerciales con la excepción del destino Habana, la campaña de descrédito a la colaboración médica cubana para afectar la exportación de servicios profesionales, la limitación de enviar hasta USD 1,000 per cápita por trimestre por concepto de remesas, la prohibición de

\footnotetext{
“Desde abril de 2018 hasta marzo de 2019, el bloqueo ha causado pérdidas a Cuba en el orden de los 4 mil 343, 6 millones de dólares (...). A precios corrientes, los daños acumulados durante casi seis décadas de aplicación de esta política alcanzan la cifra de 138 mil 843, 4 millones de dólares. Tomando en cuenta la depreciación del dólar frente al valor del oro en el mercado internacional, el bloqueo ha provocado perjuicios cuantificables por más de 922 mil 630 millones de dólares, valor que representa un decrecimiento del 1,2 por ciento con respecto al período anterior, debido a la disminución del precio del oro en 1,6 por ciento." (MINREX 2019: 5-6).
} 
enviar remesas vía Western Union a la isla excepto desde los Estados Unidos, entre otras acciones.

Las remesas constituyen una importante fuente de generación de divisas en la mayoría de los países del Gran Caribe y, en el caso de Cuba, juegan un rol central. Entre 2008 y 2018 las remesas en efectivo enviadas aumentaron sistemáticamente. De USD 1,447.06 millones en 2008, pasaron a USD 3,691.68 millones en 2018. El 90\% provino de los Estados Unidos (Morales 2019).

En 2015, solamente entre el $43 \%$ y el $46 \%$ del ingreso promedio de los hogares cubanos se obtuvo a través del salario formal (Galtés Galeano 2017; Torres 2017). Personas desempleadas con acceso a remesas pueden obtener ingresos mayores que los empleados en el sector estatal a pesar de los incrementos salariales de 2005, 2014 y 2019, situación que profundiza la desigualdad de ingresos antes mencionada.

Otra limitante de naturaleza cuasi permanente es el mapa demográfico cubano caracterizado por el envejecimiento poblacional y movimientos migratorios, sobre todo de profesionales jóvenes que salen del país ya sea de manera temporal o definitiva. Desde 1978, el país acumula bajo crecimiento poblacional e incluso registra años de decrecimiento con una fecundidad por debajo de la tasa de reemplazo generacional. La mortalidad infantil en menores de 5 años alcanza 5.5 por cada mil nacidos vivos y la esperanza de vida al nacer es de 78 años. Casi 20\% de los habitantes cuentan con 60 años y más. El valor proyectado para 2030 estima en más de 30\% la población cubana mayor de 60 años (Grupo de Trabajo Nacional sobre Población y Desarrollo 2017: 1).

\section{ALGUNAS IDEAS PARA AVANZAR LA REFORMA}

Tras casi una década desde que fuera aprobado el programa de los Lineamientos, aún no se alcanzan los propósitos declarados. Si bien se han materializado cambios positivos, la reactivación y metamorfosis económicas no han ocurrido en la magnitud proyectada mientras aumenta la desigualdad social. De manera general, puede resumirse que las transformaciones emprendidas en la gestión económica son de naturaleza gradual sin llegar a tocar "la columna vertebral del sistema centralizado y el monopolio de la empresa estatal" (Vidal Alejandro 2019).

Perdura el déficit de la balanza de pagos, déficit fiscal, un insatisfecho apetito importador, motivación reducida por el trabajo en el sector estatal de la economía, expansión limitada de las formas cooperativas y los pequeños y medianos emprendimientos, insuficiente inversión, y distorsiones en el sistema monetario y cambiario, entre otros problemas.

Las insuficiencias anteriores se agravan ante la persistencia de trabas internas que obstaculizan mecanismos económicos básicos garantes del funcionamien- 
to del ciclo producción, distribución, cambio y consumo propio de cualquier ecosistema económico moderno. Tal y como ya había ocurrido cuando la aplicación de previos programas de transformaciones ha primado la incoherencia entre lo que se quiere lograr con los Lineamientos, por un lado, y la política económica y los instrumentos para su ejecución, por otro. ${ }^{8}$

Dentro del conjunto de propuestas a aplicar para corregir tal desviación y en el afán de continuar y profundizar la reforma, contando ahora con la ventaja de contar con un marco constitucional que otorga amparo legal al conjunto de transformaciones a emprender, me hago eco de la necesidad de: (i) sustituir la lista que autoriza algo más de un centenar de actividades a ejercer por parte del sector privado por una lista negativa; (ii) eliminar las agencias intermediadoras para la contratación de trabajadores locales; (iii) autorizar al sector privado el asociarse con el capital extranjero; (iv) autorizar a cadenas de tiendas extranjeras a operar en Cuba; (v) dinamitar el monopolio sobre la actividad de comercio exterior ejercido desde el Ministerio del Comercio Exterior y la Inversión; (vi) permitir a los agricultores privados la compra de medios de trabajo como equipos para la construcción y tractores; (vii) promover formas de cogestión y autogestión obrera dentro de la empresa estatal socialista (Pérez Villanueva 2019; D’Angelo Hernández 2020; Pajón Espina y Pérez Villanueva 2020; Pérez Villanueva 2020a). Tales modificaciones incidirían positivamente en el propósito de "desatar las fuerzas productivas" y limar incongruencias entre el espíritu de los Lineamientos y las políticas (no) aplicadas.

Desatar, destrabar, liberar las fuerzas productivas: ese reconocimiento a la necesidad imperiosa de aceitar los vasos comunicantes entre sectores, actores y mercados que conforman el ecosistema económico cubano se ha convertido en una constante de la narrativa del gobierno, reafirmada en la convocatoria hecha a la ciudadanía de Pensar como País. ${ }^{9}$ Esto merece atención ya que la referencia a eliminar obstáculos a las relaciones económicas no solo apunta a facilitar y promover la participación del sector privado sino también de la empresa estatal y del conjunto de los actores económicos. De lo que se trata es de "aprovechar las reservas productivas existentes por todas las formas de propiedad" (Pérez Villanueva 2020a).

8 En referencia a la estrategia de desarrollo aplicada en Cuba entre 1965 y 1970, decía Pérez Villanueva (2008): “Así, por ejemplo, la utilización inadecuada de las relaciones mercantiles, o de los instrumentos de precio y costo, o el desconocimiento de la necesidad de un sistema impositivo diferenciado para los distintos sectores de propiedad, o la utilización de la centralización de forma excesiva como instrumento de control, constituyeron elementos que obstaculizaron un mejor resultado de las medidas de política económica aplicadas." (Pérez Villanueva 2008: 36). Tal descripción mantiene su validez al hacer el balance de las medidas de política introducidas hasta 2019 al calor de los Lineamientos.

En la emisión del 13 de septiembre de 2019 del programa televisivo cubano Mesa Redonda, espacio de más de 20 años en pantalla que, de lunes a viernes, se dedica a comentar temas de actualidad nacional e internacional, el Decano de la Facultad de Economía de la Universidad de La Habana Dr. Antonio Romero abordó el tema de "liberar las fuerzas productivas", lo que motivó un intenso debate en las redes sociales y medios de prensa. Desde entonces, la referencia a remover obstáculos que constriñen el desarrollo de las fuerzas productivas como tarea de primer orden para la economía cubana ha ganado en visibilidad y pasó a ser tema recurrente en el discurso público y las redes sociales. 
El reclamo de desatar las fuerzas productivas ha sido reiterado, en varias ocasiones, por el Presidente Díaz-Canel Bermúdez -reunión del Consejo de Ministros en diciembre de 2019, visita de gobierno a la provincia de Sancti Spíritus en enero de 2020, entre otras ocasiones. Contrasta aquí como, desde el discurso oficial se proyecta un compromiso continuado con el programa de los Lineamientos mientras la realidad de la política implementada contradice la voluntad política y el consenso social. Tal parece que, desde el gobierno, si bien se mantiene el compromiso de avanzar en los cambios, se espera a encontrar una fórmula de reforma "sinflictiva" (sin conflictos) que no trastoque los fundamentos del modelo actual. Soluciones de este tipo se antojan harto difíciles en las circunstancias actuales.

La desconexión entre lo acordado y lo ejecutado ha provocado que el programa de reforma sea calificado de insuficiente cuando, en realidad, se dista mucho aún de una ejecución parcialmente satisfactoria de su contenido para una apreciación concluyente de su valía y posibilidades intrínsecas de transformación. De acuerdo con Carranza (2020): “(...) si bien la reforma ha sido mayoritariamente aceptada, y hasta bien "conceptualizada", incluida en lineamientos y recogida por una nueva constitución aprobados todos esos documentos por el Partido y el Parlamento, es sistemáticamente retrasada y mutilada, atrapada en medio de una burocracia que no es capaz de moverse adelante, salir de su zona de confort y romper esa parálisis paradigmática que la afecta" (Carranza 2020).

En ocasión del VII Congreso del PCC, celebrado en 2016, se reconoció que solamente habían sido implementados algo más del 20\% de las acciones reconocidas dentro de los Lineamientos, mientras que casi el $80 \%$ se encontraba en proceso de implementación (PCC 2017). Con el propósito de relanzar la reforma, en la reunión se aprobaron dos nuevos documentos: (i) Conceptualización del modelo económico y social cubano de desarrollo socialista y (ii) Lineamientos de la Política Económica y Social del Partido y la Revolución para el periodo 2016-2021 para así dotar de mayor precisión y claridad a las transformaciones a ejecutar. Los mismos fueron complementados con la aprobación en 2019 del Plan Nacional de Desarrollo Económico y Social hasta 2030 que se subdivide en tres etapas: (i) del 2019 al 2021; (ii) del 2022 al 2026 y (iii) del 2017 al 2030, y se concentra en seis sectores estratégicos: turismo, producción de alimentos, industria biotecnológica y farmacéutica, servicios profesionales en el exterior, sector electro energético y construcción (Martinez y Barbosa 2019). En la última sesión anual de la ANPP en diciembre de 2019, se aprobaron 28 medidas encaminadas a perfeccionar el funcionamiento de la empresa estatal socialista, aspecto medular del modelo económico cubano. Tales medidas habrían de allanar el camino a la aprobación de una Ley de Empresas anunciada para abril de 2022, que esperamos no descuide las regulaciones relativas a la creación y funcionamiento de las pequeñas y medianas empresas, así como de las microempresas.

Amén de la cautela, conservadurismo y compás de espera a la llegada de tiempos mejores que pareciera haber primado en el núcleo de los tomadores de 
decisiones y ejecutores de la política en $\mathrm{Cuba}^{10}$ y que ha derivado en acciones inconsecuentes, e incluso contradictorias, entre medidas aprobadas y políticas (no) ejecutadas, reiteramos que el entorno regional y global ha conspirado en contra del espíritu más audaz que yace en el núcleo de los cambios proyectados al modelo cubano. La inestabilidad de la economía global que no encuentra una senda de crecimiento firme desde 2008 no coopera con el avance de los $\mathrm{Li}$ neamientos. De acuerdo a CEPAL, entre 2011 y 2019 la tasa media de crecimiento económico a nivel global fue del 2.8\%, inferior al 3.4\% registrado entre 1997 y 2006. En 2019, la economía mundial registró su peor desempeño desde 2009, con una tasa de crecimiento del $2.5 \%$ (CEPAL 2020).

A este panorama difícil se suma la pandemia de la covid-19, enfermedad que irrumpió a finales de 2019. Sus efectos, indefectiblemente, forzarán ajustes significativos en la política económica y obligarán al Estado cubano a perfeccionar su función como ente central de la planificación para gestionar los escasos recursos, proteger a los ciudadanos -en particular, a los grupos más vulnerables- y estimular la economía cuando se superen los momentos más críticos de trasmisión de la enfermedad. ${ }^{11}$

Este adverso panorama exterior donde se combinan la creciente hostilidad de la Administración Trump, la grave crisis venezolana y la depresión económica aconseja identificar y explotar, de manera ágil, las escasas oportunidades disponibles en el futuro próximo. En aras de navegar y quizás progresar en este escenario dificilísimo para Cuba es esencial no abandonar la reforma iniciada pues los problemas socioeconómicos identificados y a superar, lejos de desaparecer, se tienden a expandir y profundizar en la coyuntura actual.

Consideramos que, de implementarse el conjunto de cambios recogidos en los Lineamientos, se facilitaría el ajuste y mejor desempeño de la economía en las nuevas circunstancias. Por ejemplo, las acciones más recientes ejecutadas en pos de la modernización de la planta energética, la infraestructura de comunicaciones y la informatización de la sociedad probaron su valía en un contexto donde el acceso a la información y las comunicaciones demandaron del uso intensivo de las redes de telefonía y datos móviles.

A su vez, razonamos que las circunstancias económicas, políticas y sociales de Cuba a fines de 2019 obligarán a una relectura de los Lineamientos y a recalibrar las prioridades de la política económica y del plan de desarrollo trazado hasta

10 La visita del entonces Presidente Obama a La Habana en 2016 y su apoyo abierto al sector privado de la isla, de conjunto con la creciente hostilidad desplegada por el presidente Trump, han reforzado a lo interno el concepto de plaza sitiada.

11 Los impactos esperados de la crisis por venir se expresarían en Cuba en "disminución de la disponibilidad de divisas (desaparición del mercado turístico, dificultades en la toma de créditos por impagos a países y acreedores comerciales, probable disminución de remesas, disminución de exportaciones de algunos rubros) y la imposibilidad de sostener la habitual factura de bienes importados (de consumo con énfasis en alimentos, e intermedios vitales para los procesos productivos)" (Pajón Espina y Pérez Villanueva 2020). Lo anterior se traduciría en presiones inflacionarias, reducción de los ingresos de la población y el fisco, y el aumento de la informalidad y precarización laborales. 
2030. Los ajustes de política como respuestas a dinámicas exógenas de diversa índole serán motivados por el carácter globalizado de las relaciones económicas internacionales y sus consecuencias para los PEID. En las circunstancias presentes, Cuba no es capaz de generar el suficiente ahorro interno para sostener los montos de inversión que demandan sus metas de crecimiento y desarrollo económicos. Tampoco puede suplir la gama variada de bienes y servicios que requiere debido a la dotación dada de recursos naturales y los costos relativamente altos que ha de encarar en la construcción/modernización de infraestructura y comunicaciones. Desde su condición de PEID, enfrentada además a la superpotencia económica regional y con su principal socio económico en crisis profunda, la isla está forzada a ponderar las decisiones sobre qué producir y qué exportar, desde el reconocimiento de la imposibilidad de eliminar su marcada dependencia externa en el corto y mediano plazos.

El asunto radica en aumentar la resiliencia a partir de una selección estratégica de actividades a fomentar considerando la experticia y las ventajas competitivas desarrolladas. Tales apuestas deben responder, en lo posible, a escenarios que incorporen variables y derroteros diferentes, de forma tal que se cuente con un espectro amplio de combinaciones que permitan minimizar riesgos y recalibrar la ruta del plan económico y de desarrollo de manera ágil. Las experiencias de otros PEID económicamente exitosos demuestran la importancia de contar con mano de obra altamente profesional y entrenada, capaz de ser recalificada en periodos de tiempo relativamente cortos para adecuarse a las nuevas circunstancias dictadas desde el exterior. La inversión acumulada en educación, ciencia y tecnología, de conjunto con la exportación de servicios profesionales, son elementos a favor de Cuba en este esfuerzo de volverse más resiliente (Laguardia Martinez 2019).

Cuba debería prestar más atención a su condición de PEID e incorporarla a la discusión, diseño y ejecución de su política económica. Este cambio de mentalidad podría facilitar la identificación de prioridades de inversión, exportaciones, papel del país en el sistema de relaciones internacionales y visión del desarrollo. Los PEID han de aprender a convivir con cierta "deformación estructural", consustancial a su geografía y lo que de esta se deriva. Reconocer estas limitaciones y asumirlas resultaría altamente beneficioso en la voluntad de fortalecer los niveles de resiliencia económica, política, social y ambiental.

Tales acomodos encajan en los ajustes esperados que los países de menor desarrollo habrán de asumir en un panorama de contadas opciones de política y recursos escasos. En estas naciones, se prevé que "los procesos de recuperación se basen en dinámicas de reindustrialización, fortalecimiento del estado, afianzamiento de modelos con creciente incorporación de tecnología, automatización y proyección online. A su vez, es de esperar que los productores intenten acortar en lo posible las cadenas globales de valor, buscando suministradores más cercanos y mayores stocks, priorizando redundancia por sobre eficiencia." (Pajón Espina y Pérez Villanueva 2020). 
A partir de este análisis subrayo nuevamente la importancia que tiene para Cuba y su proceso de reforma el no descuidar sus relaciones internacionales, específicamente en su dimensión regional. El panorama actual, que nos ha recordado el carácter global de la civilización y, por ende, la necesidad de reforzar estrategias conjuntas en la solución de problemas transnacionales nos reafirma en la importancia de la integración y la cooperación regionales, sobre todo la cooperación Sur-Sur.

Cuba mantiene una historia exitosa de cooperación, en particular en los ámbitos de salud y educación. Desde la cooperación se abren posibilidades para aumentar las exportaciones de servicios profesionales, tecnologías, productos farmacéuticos y biotecnológicos, entre otros. Avanzar en una reforma económica que posibilite una mayor inserción internacional en medio de las presiones que impone el bloqueo/embargo estadounidense, es fundamental. Considérese además que, a nivel global, el sistema económico y social dominante es contrario al proyecto del Socialismo cubano. Aquí subrayo que la reforma del modelo cubano no estará completa ni será exitosa si descuida la equidad distributiva, el perfeccionamiento de la institucionalidad civil y política, y el aumento de la participación ciudadana en la toma de decisiones y evaluación de la política en el marco de una mayor justicia social.

\section{COMENTARIOS FINALES}

El análisis de la economía cubana y los impactos de la aplicación de los Lineamentos hasta 2019 nos permite concluir que el programa aprobado ha sido implementado de manera parcial, inconexa y contradictoria. Su ejecución incompleta ha conspirado en contra de la revitalización de la economía, que además se ha visto constreñida a operar en condiciones externas poco favorables asociadas, en lo fundamental, a la hostil política de la Administración Trump y el bloqueo/embargo estadounidense, la crisis venezolana y la sucesión de eventos climatológicos extremos. Este panorama desfavorable se agudizará en 2020 tras los efectos de la covid-19, cuyos efectos globales impactarán gravemente a Cuba que, en su condición de PEID, es altamente susceptible a shocks externos y cuenta con recursos limitados.

En 2019, la sociedad cubana fue testigo de un evento de importancia capital no solo para el ordenamiento político y jurídico de la nación sino para facilitar la implementación de la reforma económica. Nos referimos a la aprobación y puesta en vigor de la nueva Constitución que incluye modificaciones al sistema económico y da carácter legal a las trasformaciones en el funcionamiento y gestión económicos incluidas dentro de los Lineamientos. La Constitución necesita de leyes complementarias claves para la modificación del modelo económico cubano como son la Ley de Procedimiento Civil, Administrativo, Laboral y Económico, y la Ley de Empresas, entre otras normativas jurídicas. 
En medio de un escenario adverso como el que se presenta desde inicios de 2020, considero que el país cuenta con reservas, fortalezas y posibilidades para recuperar la economía y adelantar su programa de desarrollo socioeconómico con justicia social. Avanzar en el cumplimiento de la reforma, ajustar prioridades, atreverse a intentar nuevos caminos y abandonar fórmulas recicladas que nunca han funcionado ayudaría en el diseño y ejecución de la política y al saneamiento del ecosistema económico cubano.

Impulsar los cambios económicos acordados es un primer paso, pero no el único. Tales cambios urgen de ser acompañados de una política social y de mecanismos de participación ciudadana que se traduzcan en la elevación de la calidad de vida de los individuos y en la formación de una sociedad más justa, próspera, comunicada, inclusiva y solidaria. En este escenario, la nueva constitución deviene un instrumento guía utilísimo pues, a la vez que reconoce el nuevo contrato social entre el Estado y la ciudadanía, establece la ampliación y protecciones a los derechos de los actores sociales llamados a jugar un rol importante en la reforma económica.

\section{REFERENCIAS}

Alonso Tejada, Aurelio. 2009. El laberinto tras la caída del muro. Buenos Aires: Ruth Casa Editorial - Consejo Latinoamericano de Ciencias Sociales (CLACSO).

Álvarez, Elena. 1998. “Cuba: un modelo de desarrollo con justicia social." Ponencia presentada para el XXI Congreso de la Asociación de Estudios Latinoamericanos (LASA). Chicago, Illinois, 24-26 de septiembre.

ANPP. Asamblea Nacional del Poder Popular. 2019, 21 de diciembre. "Cronograma Legislativo. Propuesta de Leyes y Decretos Leyes. Período 2019- 2022". Recuperado el 13 de julio de 2020 de http://www.parlamentocubano.gob.cu/wp-content/uploads/ ANEXO-del-Acuerdo-del-Programa-Legislativo-Cuarto-POS-IX-Leg.pdf

Barbería, Lorena. 2008. "Remesas, pobreza y desigualdad en Cuba." Espacio Laical (2):18-21.

Carranza, Julio. 2020, 23 de abril. "Sobre las antinomias presentes en la actual situación de pandemia." El Estado como tal. El blog de Pedro Monreal sobre Cuba. Recuperado el 25 de abril de 2020 de https://elestadocomotal.com/2020/04/23/julio-carranza-sobre-las-antinomias-presentes-en-la-actual-situacion-de-pandemia/ .

Constitución de la República de Cuba. 2019. Recuperado el 22 de abril de 2020 de http:// www.granma.cu/file/pdf/gaceta/Nueva\%20Constituci\%C3\%B3n\%20240\%20KB-1. pdf .

Cubadebate. 2015, 7 de septiembre. "El 24 \% de los jóvenes en Cuba trabajan en el sector no estatal." Recuperado el 22 de abril de 2020 de http://www.cubadebate.cu/noticias/2015/09/07/el-31-de-los-jovenes-en-cuba-trabaja-en-el-sector-no-estatal/ .

CEPAL. Comisión Económica para América Latina y el Caribe. 2019. Estudio Económico de América Latina y el Caribe. Recuperado el 27 de abril de 2020 de https://repositorio. cepal.org/bitstream/handle/11362/44674/221/S1900414_es.pdf .

CEPAL. Comisión Económica para América Latina y el Caribe 2020, 3 de abril. América Latina y el Caribe ante la pandemia del COVID-19. Efectos económicos y sociales. Informe Especial COVID-19, N. 1. Recuperado el 22 de abril de 2020 de https:/ / repositorio.cepal.org/ bitstream/handle/11362/45337/4/S2000264_es.pdf .

D’Angelo Hernández, Ovidio. 2020, 30 de marzo. "Cuba: liberar las fuerzas productivas y sociales", Inter Press Service en Cuba. Recuperado el 27 de abril de 2020 de https: / /www. ipscuba.net/economia/cuba-liberar-las-fuerzas-productivas-y-sociales/ . 
Espina Prieto, Mayra P. 2008. “Desigualdad y política social en Cuba hoy", ponencia presentada en la Conferencia The Future of Social Justice in Cuba, Bellagio Conference Centre, Bellagio, Italia, 27-29 de mayo.

Figueredo Reinaldo, Oscar, Dianet Doimeadios Guerrero, José Raúl Concepción, Edilberto Carmona Tamayo e Irene Pérez, 2018, 21 de diciembre. “¿Cuáles son los principales cambios en el Proyecto de Constitución?" Cubadebate. Recuperado el 2 de julio de 2020 de http://www.cubadebate.cu/especiales/2018/12/21/cuales-son-los-principales-cambios-en-el-proyecto-de-constitucion/\#.XwH3SG1KjIU .

Figueredo Reinaldo, Oscar, Lissett Izquierdo Ferrer y Edilberto Carmona Tamayo. 2020, 7 de febrero. "Cuba en Datos: Más cubanos se sumaron a trabajar en 2019", Cubadebate. Recuperado el 22 de abril de 2020 de http://www.cubadebate.cu/especiales/2020/02/07/cuba-en-datos-mas-cubanos-se-sumaron-a-trabajar-en-2019/\#. XqHzyv1KjIU .

Galtés Galeano, Indira. 2017. “Desigualdad de ingresos en Cuba: ¿qué papel juegan los salarios?" En Miradas a la Economía Cubana. Un acercamiento a la "actualización" seis años después, editado por Ricardo Torres Pérez y Dayma Echevarría León. La Habana: Ruth Casa Editorial, 68-80.

García Castro, Teresa y Raudiel Peña Barrios. 2019, 10 de abril. “Cuba tiene nueva Constitución: ¿qué es lo próximo?" Washington Office on Latin America. Recuperado el 2 de julio de 2020 de https://www.wola.org/es/analisis/cuba-tiene-nueva-constitucion/ .

Grupo de Trabajo Nacional sobre Población y Desarrollo. 2017, septiembre. “Cuba: Informe a la Tercera Reunión de la Conferencia Regional sobre Población y Desarrollo de América Latina y el Caribe". Lima, Perú en agosto de 2018. Recuperado el 22 de abril de 2020 de https:/ / crpd.cepal.org/3/sites/crpd3/files/informe_cuba.pdf .

Laguardia Martinez, Jacqueline. 2019. "Cuba: A Caribbean SIDS Reinventing Itself". En Development, Political, and Economic Difficulties in the Caribbean, editado por Ann Marie Bissessar. London: Palgrave Macmillan, 215-233.

Martínez García, Yisel y Nuria Barbosa León. 2019, 11 de abril. “Prioridades del Plan Nacional de Desarrollo hasta 2030", Granma. Recuperado el 22 de abril de 2020 de http:/ / www.granma.cu/cuba/2019-04-11/prioridades-del-plan-nacional-de-desarrollo-hasta-2030-11-04-2019-23-04-33 .

Mesa-Lago, Carmelo. 2019, enero - febrero. "El "enfriamiento" de la economía cubana" Nueva Sociedad (NUSO) N. 279, Recuperado el 22 de abril de 2020 de https://nuso.org/ articulo/el-enfriamiento-de-la-economia-cubana/ .

MINREX. Ministerio de Relaciones Exteriores de la República de Cuba. 2019, julio. "Informe de Cuba sobre la Resolución 73/8 de la Asamblea General de las Naciones Unidas. Necesidad de poner fin al Bloqueo Económico, Comercial y Financiero Impuesto por los Estados Unidos de América contra Cuba". Recuperado el 2 de julio de 2020 de http:/ /www. minrex.gob.cu/sites/default/files/2019-09/Cuba\%20vs\%20Bloqueo.pdf .

Monreal González, Pedro. 2017a, 25 de abril. “Desigualdad en Cuba: ¿combatiendo la riqueza o la pobreza?", Cubaposible. Recuperado el 22 de abril de 2020 de https:/ / cubaposible. com/desigualdad-cuba-combatiendo-la-riqueza-la-pobreza/.

Monreal González, Pedro. 2017b, 14 de noviembre. “Un programa de estabilidad económica para Cuba", Cubaposible. Recuperado el 22 de abril de 2020 de https://cubaposible. $\mathrm{com} /$ programa-estabilidad-economica-cuba/.

Morales, Emilio. 2019, 27 de septiembre. "Remesas, ¿una ruta de inversión para los cubanos?", The Havana Consulting Group and Tech. Recuperado el 27 de abril de 2020 de http:/ / www.thehavanaconsultinggroup.com/es-es/Articles/Article/69?AspxAutoDetectCookieSupport $=1$.

ONEI. Oficina Nacional de Estadística e Información. 2019. Anuario Estadístico de Cuba 2018. Edición 2019. Recuperado el 20 de abril de 2020 de http://www.onei.gob.cu/ node/14211.

Pajón Espina, David J. y Omar Everleny Pérez Villanueva. 2020, 4 de mayo. “Cuba: urgencias económicas actuales para un contexto post COVID-19", Cuba Capacity Building Project 
"Horizonte Cubano", Columbia Law School. Recuperado el 3 de julio de 2020 de https://horizontecubano.law.columbia.edu/content/cuba-urgencias-economicas-actuales-para-un-contexto-post-covid-19.

PCC. Partido Comunista de Cuba. 2011. Lineamientos de la Política Económica y Social del Partido y la Revolución. Documento presentado en el VICongreso del PCC, La Habana, Cuba. Recuperado el 29 de marzo de 2020 de http://www.cuba.cu/gobierno/documentos/2011/esp/1160711i.pdf .

PCC. Partido Comunista de Cuba. 2017. Actualización de los Lineamientos de la Política Económica y Social del Partido y la Revolución para el periodo 2016-2021 aprobados en el $7^{\text {mo }}$ Congreso del Partido en abril de 2016 y por la Asamblea Nacional del Poder Popular en julio de 2016. Documento presentado en el VII Congreso del PCC, La Habana, Cuba. Recuperado el 29 de marzo de 2020 de http:/ / www.granma.cu/file/pdf/gaceta/01Folleto.Lineamientos-4.pdf

Pérez Villanueva, Omar Everleny. 2008. “La estrategia económica cubana: medio siglo de socialismo", Cahiers des Amériques latines, 57-58. Recuperado el 29 de abril de 2020 de http://journals.openedition.org/cal/1206 .

Pérez Villanueva, Omar Everleny. 2019, 31 de agosto. “Medidas económicas necesarias para Cuba", Inter Press Service en Cuba. Recuperado el 27 de abril de 2020 de https: / /www. ipscuba.net/economia/medidas-economicas-necesarias-para-cuba/ .

Pérez Villanueva, Omar Everleny. 2020a, 24 de enero. "La economía cubana en 2019, ¿no decrece?", Inter Press Service en Cuba. Recuperado el 27 de abril de 2020 de https:// www.ipscuba.net/economia/la-economia-cubana-en-2019-no-decrece/ .

Pérez Villanueva, Omar Everleny. 2020b, 30 de marzo. "La falta de divisas en Cuba", OnCubaNews. Recuperado el 27 de abril 2020 de https://oncubanews.com/opinion/la-faltade-divisas-en-cuba/ .

Rodríguez, José Luis. 2016, 14 de abril. “Los Lineamientos para la Política Económica y Social y su evolución 2011-2016", Cubadebate. Recuperado el 29 de marzo de 2020 de http:/ / www.cubadebate.cu/opinion/2016/04/14/los-lineamientos-para-la-politica-economica-y-social-y-su-evolucion-2011-2016/ .

Rodríguez, José Luis. 2019a, 17 de febrero. “Cuba y su economía en 2019: Un año de avances en medio de dificultades (IV)", Cubaperiodistas Recuperado el 24 de abril 2020 de https://www.cubaperiodistas.cu/index.php/2020/02/cuba-y-su-economia-en-2019un-ano-de-avances-en-medio-de-dificultades-iv/ .

Rodríguez, José Luis. 2019b, agosto. "Impactos para Cuba de la evolución más reciente de la economía mundial". En Resumen sobre la evolución de la economía mundial. Primer semestre de 2019, editado por José Luis Rodríguez y Ramón Pichs Madruga. La Habana, Centro de Investigaciones de la Economía Mundial (CIEM), 92 - 100.

Rodríguez, José Luis. 2019c. "Notas sobre la economía cubana y latinoamericana: sesenta años después del triunfo de la Revolución cubana". En Cuba en revolución: miradas en torno a su sesenta aniversario, editado por Luis Suárez Salazar, Buenos Aires: CLACSO, $49-82$.

Rosabal, Heriberto. 2013, 15 de octubre. "Marino Murillo: El modelo cubano es socialista", Cubadebate. Recuperado el 29 de abril de 2020 de http://www.cubadebate.cu/especiales /2013/10/15/marino-murillo-el-modelo-cubano-es-socialista/comment-page-3/\#.XqIXl_1KjIU .

Romero, Antonio F. 2017. "Cuba: transformación económica y relaciones con el Caribe en el escenario post 17-D". En Cuba: empresas y economía, editado por Maribel Aponte Garcia; Luis Suárez Salazar e Isabel Allende Karam. Buenos Aires: CLACSO, 47 - 68.

Suárez Salazar, Luis. 2017. "La "Actualización" del Socialismo cubano: otra mirada desde sus utopías". En Cuba: empresas y economía, editado por Maribel Aponte Garcia, Luis Suárez Salazar e Isabel Allende Karam. Buenos Aires: CLACSO, 27 - 46.

Tirado, Arantxa. 2018, 23 de julio. "Cuba: nueva Constitución para una nueva fase de la Revolución", Centro Estratégico Latinoamericano de Geopolítica (CELAG). Recupe- 
rado el 2 de julio de 2020 de https://www.celag.org/cuba-nueva-constitucion-para-una-nueva-fase-de-la-revolucion/ .

Torres Pérez, Ricardo. 2017. "El proceso de actualización del modelo económico y social de Cuba". En Pensamiento Propio: Cuba y el proceso de actualización en la era de Trump, editado por Andrés Serbin, Buenos Aires: Centro de Estudios Globales y Regionales, 57-80.

Triana Cordoví, Juan. 2017. “Economía cubana 2016 y 2017: La coyuntura y los retos del crecimiento". En Miradas a la Economía Cubana. Un acercamiento a la «actualización» seis años después, editado por Ricardo Torres Pérez y Dayma Echevarría León. La Habana: Ruth Casa Editorial, 37-48.

Serbin, Andrés. 2019, 7 de marzo. "Cuba: una Compleja Transición”, Análisis Carolina. Recuperado el 24 de abril de 2020 de https:/ / www.fundacioncarolina.es/wp-content/ uploads/2019/03/AC2.pdf .

Valdés Paz, Juan. 2014. "Prólogo". En Algunas Claves para Pensar la Pobreza en Cuba desde la Mirada de Jóvenes Investigadores, editado por María del Carmen Zabala Argüelles. La Habana: Publicaciones Acuario, 9-13.

Vidal Alejandro, Pavel. 2019, 24 de enero. "La economía cubana en 2018: otro año sin colapso y sin progreso", Cuba Capacity Building Project "Horizonte Cubano", Columbia Law School. Recuperado el 27 de abril de 2020 de https: / /horizontecubano.law.columbia. edu/content/la-economia-cubana-en-2018-otro-ano-sin-colapso-y-sin-progreso .

Recibido: 29 de abril de 2020

Aceptado: 8 de julio de 2020

Jacqueline Laguardia Martínez es doctora en Economía por la Universidad de La Habana, Cuba. Profesora del Instituto de Relaciones Internacionales de la University of the West Indies, campus St. Augustine. Correo electrónico: jacqueline.laguardia-martinez@sta.uwi.edu. 
